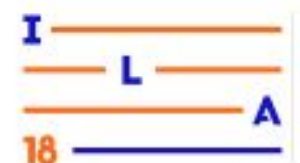

\title{
ACCESIBILIDAD COGNITIVA DEL ENTORNO URBANO: PICTOGRAMAS PARA LA NAVEGACIÓN ESPACIAL DE PERSONAS CON DISCAPACIDAD INTELECTUAL
}

\author{
COGNITIVE ACCESSIBILITY IN THE URBAN ENVIRONMENT: \\ PICTOGRAMS FOR THE SPATIAL NAVIGATION OF PEOPLE WITH \\ COGNITIVE IMPAIRMENT
}

\author{
María Ignacia von Unger, Bach. \\ Antonella Pastén, Bach. \\ Katherine Exss, MA. \\ Herbert Spencer, MDes. \\ Vanessa Vega, $\mathrm{PhD}$.
}

(1) Escuela de Arquitectura y Diseño, Pontificia Universidad Católica de Valparaíso e-mail: manavonunger@gmail.com

(2) Escuela de Arquitectura y Diseño, Pontificia Universidad Católica de Valparaíso e-mail: antonellapastenbernales@gmail.com

(3) Escuela de Arquitectura y Diseño, Pontificia Universidad Católica de Valparaíso e-mail: kexss@ead.cl

(4) Escuela de Arquitectura y Diseño, Pontificia Universidad Católica de Valparaíso e-mail: hspencer@ead.cl

(5) Escuela de Pedagogía, Pontificia Universidad Católica de Valparaíso e-mail: vanessa.vega@pucv.cl

Accesibilidad cognitiva, pictogramas, discapacidad intelectual

El siguiente artículo da cuenta de una investigación y proceso de co-creación de un sistema pictográfico que apunta a ofrecer apoyos para aumentar la autodeterminación en adultos con discapacidad intelectual al navegar por la ciudad, específicamente durante el uso del metro-tren de Valparaíso, Chile. La problemática se aborda desde una metodología interdisciplinaria y colaborativa.

Cognitive accessibility, pictograms, cognitive impairment

The following article refers to the research and co-creation process of a pictographic system that aims to offer support to increase self-determination in adults with cognitive impairment, when navigating through the city, specifically when using the underground train in Valparaiso, Chile. The research is approached from an interdisciplinary and collaborative methodology. 


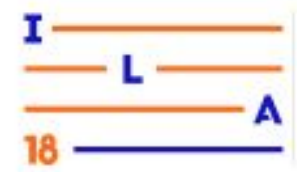

\section{Introducción}

Las personas con discapacidad intelectual se caracterizan principalmente por tener dificultades para aprender o memorizar cosas, tomar decisiones, navegar y comprender los espacios físicos; generando dependencia en el día a día (Bosch \& Gharaveis, 2016). Si se ofrecen los apoyos pertinentes, el funcionamiento de las personas debiera mejorar (AAIDD, 2010).

En Chile, el 5,4\% de la población presenta algún grado de discapacidad intelectual (SENADIS, 2016). Este porcentaje incrementa en la tercera edad, por lo cual se espera un aumento sustancial de esta condición en los próximos años con el envejecimiento de la población (Rodríguez-Sánchez, 2011). Es por esto que se torna imperativo encontrar una solución a los problemas que se desprenden del entorno urbano, como la dependencia de la memorización, la falta de formatos complementarios (visual, auditivo, multigráfico), la necesidad de utilizar habilidades organizativas complejas, y la falta de un lenguaje que se amolde a la comprensión de todos los receptores (Fundación ONCE, 2009).

El caso de Valparaíso presenta una mayor complejidad debido a que es una ciudad con una pequeña trama planificada ortogonal y una gran zona de 42 cerros donde el crecimiento ha sido orgánico. Esta expansión natural no entrega un sistema urbano fácilmente comprensible para quienes deben recorrer la ciudad (Kapstein, 2009).

En el caso de los servicios, la comprensión, la predicción o anticipación y la orientación temporoespacial, son los requerimientos básicos para su uso. En este contexto cualquier iniciativa que trabaje en beneficio de las personas con discapacidad intelectual apoyando su navegación por el espacio transaccional de los servicios, será útil para todas las personas (Larraz, 2015), asegurando una mayor inclusión y una vida independiente.

Se habla de accesibilidad cognitiva cuando la información del entorno se estructura de tal manera, que resulta fácil o intuitiva de comprender por cualquier persona, independiente de sus capacidades cognitivas (Larraz, 2015). La accesibilidad cognitiva facilita no sólo la interacción de la persona con el espacio, sino que también la interacción entre personas (ASPADEX, 2015).

Su importancia radica principalmente en generar igualdad de condiciones y oportunidades de acceso a la información, o bien, en hacer esta brecha más pequeña para las personas con distintas capacidades cognitivas.

La persona con discapacidad intelectual será más o menos autónoma en la medida que disponga de los apoyos necesarios para actuar como estime conveniente y desarrollar sus habilidades (Puyalto, 2016). En este sentido, la autodeterminación se define como el proceso donde la acción de la persona es el principal agente causal de su vida, que le permite tomar decisiones y elecciones de manera libre y sin influencias externas no deseables (Rojas, 2004). En otras palabras, deberá tener el control de sus pensamientos y acciones para considerarse autónoma o independiente.

De acuerdo a todo lo anteriormente planteado la accesibilidad cognitiva permite una mayor independencia y autodeterminación de las personas con discapacidad intelectual, lo cual le permitirá desarrollarse plenamente, otorgándole expectativas, dignidad, responsabilidad y oportunidades, aumentando su calidad de vida (Williams, 1989; Vega \& Álvarez, 2016).

\section{Pictogramas y wayfinding}

El wayfinding es la habilidad, tanto cognitiva como conductual, de una persona para aprender y recordar rutas en un espacio, con el fin de movilizarse en él y llegar a su destino. Ésta comprende la capacidad para tomar y ejecutar decisiones, para procesar la información y para resolver problemas espaciales (Kitchin, 1994; Passini, 1984).

Se trata de un sistema de orientación espacial que favorece la accesibilidad cognitiva en el entorno urbano, ya que facilita la estrategia cognitiva para movilizarse por un espacio (García, 2012). Este sistema afecta directamente al nivel de autonomía o independencia de la persona que lo utiliza, la cual, al no tener mayores dificultades para entender y 
Interaction Latin America

Rio de Janeiro, Brasil - 2018

http://ila.ixda.org/2018

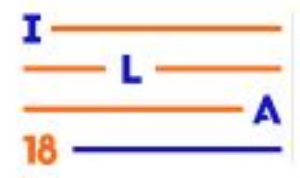

navegar el espacio, contará con la libertad para decidir qué hacer en él.

La señalética es un recurso del wayfinding que facilita la navegación del entorno urbano, básicamente porque su objetivo es orientar las decisiones y acciones de las personas en los servicios (Costa, 1987).

Cuando una persona se enfrenta a un territorio desconocido, tiende a confiar más en la información que se ubica en el lugar físico, que en sus conocimientos por experiencias previas, creencias o apreciaciones (Bosch \& Gharaveis, 2016). Es por esta razón que las referencias espaciales o hitos son tan importantes, puesto que al llamar la atención de la persona, funciona como apoyo al momento de comprender y navegar un espacio .

El uso de pictogramas para el apoyo del wayfinding en personas con discapacidad intelectual ha sido ampliamente estudiado (García, 2012; Larraz, 2015; Marquez et al, 2015; Rodrigo \& Anaut, 2016), demostrando que estos pueden facilitar la comprensión de los mensajes escritos en las señaléticas.

Si bien las personas con discapacidad intelectual son capaces de comunicarse en su vida diaria sin el uso de pictogramas, existen algunas que sí los necesitan. Lo cierto es que ellos complementan la comprensión de la información, influyendo positivamente en el desarrollo de la participación de la persona en su entorno (Rodrigo, \& Anaut, 2016).

El siguiente artículo presenta la propuesta de un sistema compuesto por ilustraciones pictográficas, que tienen como objetivo ofrecer apoyos para aumentar la autodeterminación de personas con discapacidad intelectual al momento de usar los servicios, mejorando su calidad de vida. Esto se logra a través de metodologías de trabajo basadas en el co-diseño.

Esta investigación se enmarca dentro del proyecto interdisciplinario "REIDI", conformado por profesionales de las áreas de la educación Especial, sociología, psicología, ingeniería informática y diseño.
El estar insertos en este proyecto permitió acceder a trabajar con un grupo asesor conformado por adultos con discapacidad intelectual de la región de Valparaíso, Chile, quienes fueron la principal fuente de información y posterior validación en los procesos de investigación y de diseño, respectivamente.

La participación de las personas con discapacidad intelectual se considera un factor determinante y diferenciador en esta investigación y proceso de diseño, puesto que entrega resultados cualitativos de manera empírica.

Este artículo da cuenta del proceso de co-creación de un sistema pictográfico para incidir positivamente en la autodeterminación de los adultos con discapacidad intelectual.

\section{Método}

El objetivo del estudio consistió en diseñar una propuesta pictográfica que incidiera positivamente en los niveles de autodeterminación de los adultos con discapacidad intelectual en Valparaíso, para hacer accesibles cognitivamente los servicios mediante el acompañamiento de la persona en sus transacciones. Para ello, fue necesario el trabajo interdisciplinario e inclusivo con el público objetivo.

Según Sanders (2008) al utilizar las metodologías participativas y de co-diseño, los roles se mezclan posibilitando que la persona que eventualmente recibirá el servicio sea considerada "experta en su propia experiencia". Esto juega un papel importante en la investigación, y por ende en el desarrollo de conceptos, la generación de ideas y el desarrollo del conocimiento.

Por su parte, el trabajo interdisciplinario permitió integrar las perspectivas de las distintas disciplinas académicas que se vieron involucradas. La metodología de este trabajo se llevó a cabo mediante talleres colaborativos presenciales, donde cada miembro del equipo interdisciplinario cumplía un rol específico.

Cada taller estuvo compuesto por dos momentos: en el primero el grupo asesor desarrollaba la actividad de manera grupal o individual según lo requerido. 


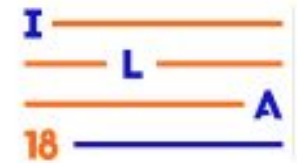

En un segundo momento se realizaba un intercambio de ideas sobre la temática abordada en el taller; opinaba tanto el grupo asesor como el equipo interdisciplinario.

Luego de cada jornada de trabajo colaborativo, el equipo interdisciplinario se reunía para analizar los hallazgos de cada taller, donde se traducían las ideas y sugerencias que entregaba el grupo asesor a la investigación y, por lo tanto, a la gráfica de las futuras ilustraciones pictográficas.

En relación a los insumos utilizados en cada taller, se tomó la decisión de utilizar recursos impresos, ya que estos permitieron focalizar el trabajo en base a los objetivos preestablecidos.

Al tratarse de una investigación y proceso de diseño empírico y cualitativo, cada miembro participante tiene un papel importante y contribuye desde su propia perspectiva. La asociación con los usuarios finales garantiza su inclusión en el desarrollo del conocimiento, la creación de la idea conceptual y el desarrollo de los productos (Aguas, 2016).

\section{Grupo asesor}

Para el cumplimiento del objetivo, se trabajó en talleres colaborativos con un grupo asesor (GA), conformado por 11 adultos con discapacidad intelectual, quienes fueron la principal fuente de información y validación de datos. Cada miembro tuvo que firmar un consentimiento informado para poder participar de esta investigación.

A continuación se presenta una tabla donde se evidencia la edad, ocupación y situación de independencia de cada miembro del grupo asesor. Se sitúa a la totalidad del grupo en un contexto, donde se detalla si la persona estudia o trabaja, si vive sola o acompañada y si es que necesita de apoyo profesional en su vida diaria. Los talleres grupales permitieron generar un entorno de trabajo cómodo y distendido, lo cual se reflejó en los posteriores hallazgos de cada taller.

\begin{tabular}{|l|l|l|l|l|}
\hline$N^{\circ}$ & Sexo & Edad & Ocupación & $\begin{array}{l}\text { Situación de } \\
\text { independencia }\end{array}$ \\
\hline
\end{tabular}

\begin{tabular}{|c|c|c|c|c|}
\hline 1 & $F$ & 22 años & $\begin{array}{l}\text { Trabaja en la } \\
\text { asociación } \\
\text { "AVANZA" sin } \\
\text { fines de lucro }\end{array}$ & $\begin{array}{l}\text { Vive con sus } \\
\text { padres y } \\
\text { hermanos }\end{array}$ \\
\hline 2 & $\mathrm{~F}$ & 31 años & $\begin{array}{l}\text { Egresada de } \\
\text { Administración } \\
\text { en la UNAB. No } \\
\text { trabaja } \\
\text { actualmente. }\end{array}$ & $\begin{array}{l}\text { Vive con sus } \\
\text { padres }\end{array}$ \\
\hline 3 & $\mathrm{~F}$ & 29 años & $\begin{array}{l}\text { Trabaja en el } \\
\text { Centro de } \\
\text { Formación } \\
\text { Técnica (CFT), } \\
\text { como apoyo en } \\
\text { la cafetería }\end{array}$ & $\begin{array}{l}\text { Vive con sus } \\
\text { padres }\end{array}$ \\
\hline 4 & $F$ & 22 años & $\begin{array}{l}\text { Estudia en la } \\
\text { asociación } \\
\text { "AVANZA" sin } \\
\text { fines de lucro }\end{array}$ & $\begin{array}{l}\text { Vive con sus } \\
\text { padres }\end{array}$ \\
\hline 5 & M & 52 años & $\begin{array}{l}\text { Es } \\
\text { vicepresidente de } \\
\text { la agrupación } \\
\text { "Líderes con } \\
1000 \\
\text { capacidades" sin } \\
\text { fines de lucro }\end{array}$ & $\begin{array}{l}\text { Vive con su } \\
\text { esposa }\end{array}$ \\
\hline 6 & $\mathrm{~F}$ & 30 años & $\begin{array}{l}\text { Trabaja en } \\
\text { Starbucks como } \\
\text { "coffee master" }\end{array}$ & $\begin{array}{l}\text { Vive con sus } \\
\text { padres y } \\
\text { hermanos }\end{array}$ \\
\hline 7 & $M$ & 43 años & $\begin{array}{l}\text { Estudia en el } \\
\text { taller "Tukuypaj" } \\
\text { sin fines de lucro }\end{array}$ & $\begin{array}{l}\text { Vive con sus } \\
\text { tíos }\end{array}$ \\
\hline 8 & $\mathrm{~F}$ & 35 años & $\begin{array}{l}\text { Trabaja de } \\
\text { asistente de } \\
\text { párvulos }\end{array}$ & $\begin{array}{l}\text { Vive con su } \\
\text { abuela y tíos }\end{array}$ \\
\hline 9 & $\mathrm{M}$ & 32 años & $\begin{array}{l}\text { No trabaja, pero } \\
\text { recibe pensión }\end{array}$ & $\begin{array}{l}\text { Vive con sus } \\
\text { padres }\end{array}$ \\
\hline 10 & $\mathrm{~F}$ & 54 años & $\begin{array}{l}\text { Trabaja en el } \\
\text { centro de } \\
\text { capacitación } \\
\text { "Suma 1" sin } \\
\text { fines de lucro }\end{array}$ & $\begin{array}{l}\text { Vive con su } \\
\text { papá }\end{array}$ \\
\hline 11 & $\mathrm{M}$ & 25 años & $\begin{array}{l}\text { Trabaja en el } \\
\text { centro de } \\
\text { capacitación } \\
\text { "Suma 1" sin } \\
\text { fines de lucro }\end{array}$ & $\begin{array}{l}\text { Vive con su } \\
\text { mamá }\end{array}$ \\
\hline
\end{tabular}

Tabla 1. Detalle de los asesores que colaboraron en esta investigación.

Como se muestra en la tabla, el grupo asesor se conforma por 7 mujeres y 4 hombres, con edades entre los 22 y los 54 años, características que le 


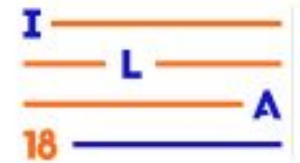

otorgan diversidad de perspectivas y experiencias a la investigación.

\section{Talleres de co-diseño}

Los instrumentos de recolección de datos consistieron en la aplicación de una sonda más cuatro talleres colaborativos. Todos se llevaron a cabo junto al grupo asesor y a los profesionales de todas las disciplinas.

En la sonda se buscó entender cuáles eran las debilidades del entorno y habilidades de las personas con discapacidad intelectual al navegar un espacio desconocido, específicamente el Museo de Historial Natural de Valparaíso, mediante un mapa impreso. En los talleres colaborativos, se validaron y tomaron las decisiones que afectarían al contenido de las ilustraciones pictográficas.

\begin{tabular}{|c|c|c|c|}
\hline Taller & Fecha & Objetivo & $\begin{array}{l}\text { Asistencia } \\
\text { GA }\end{array}$ \\
\hline Sonda & $\begin{array}{l}20 / 04 / \\
2018\end{array}$ & $\begin{array}{l}\text { Conocer la } \\
\text { manera en que } \\
\text { las personas con } \\
\text { DI entienden y } \\
\text { navegan los } \\
\text { espacios }\end{array}$ & 10 \\
\hline $\begin{array}{l}\text { Pictogramas y } \\
\text { su vínculo con el } \\
\text { espacio }\end{array}$ & $\begin{array}{l}27 / 04 / \\
2018\end{array}$ & $\begin{array}{l}\text { Conocer la } \\
\text { cantidad mínima } \\
\text { de elementos que } \\
\text { se necesitan para } \\
\text { asociar el } \\
\text { pictograma a su } \\
\text { elemento real }\end{array}$ & 11 \\
\hline $\begin{array}{l}\text { Descomposición } \\
\text { de tareas en } \\
\text { pasos }\end{array}$ & $\begin{array}{l}11 / 05 / \\
2018\end{array}$ & $\begin{array}{l}\text { Identificar los } \\
\text { pasos o etapas } \\
\text { que se necesitan } \\
\text { para hacer la } \\
\text { secuencia de una } \\
\text { tarea }\end{array}$ & 10 \\
\hline $\begin{array}{l}\text { Construcción de } \\
\text { tareas a través } \\
\text { de la asociación } \\
\text { de imágenes }\end{array}$ & $\begin{array}{l}18 / 05 / \\
2018\end{array}$ & $\begin{array}{l}\text { Conocer la } \\
\text { cantidad de pasos } \\
\text { que se necesitan } \\
\text { para entender la } \\
\text { tarea "Ir de un } \\
\text { punto a otro" }\end{array}$ & 10 \\
\hline $\begin{array}{l}\text { Capacidad } \\
\text { comunicativa de } \\
\text { las ilustraciones } \\
\text { pictográficas }\end{array}$ & $\begin{array}{l}25 / 05 / \\
2018\end{array}$ & $\begin{array}{l}\text { Nombrar los } \\
\text { pasos de la tarea } \\
\text { "Ir de un punto a } \\
\text { otro" para } \\
\text { identificar cuáles } \\
\text { pictogramas son } \\
\text { lo suficientemente }\end{array}$ & 9 \\
\hline
\end{tabular}

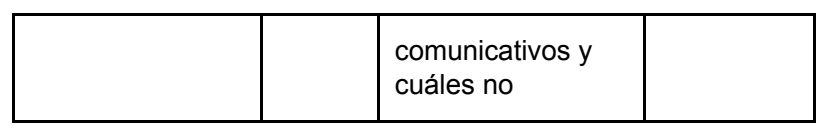

Tabla 2. Detalle de las actividades llevadas a cabo en la sonda y en cada taller de co-diseño.

\section{Accesibilidad cognitiva y movilidad}

Las ciudades contemporáneas han presentado un aumento en su complejidad, por la densidad de sus servicios y las aplicaciones de la "sociedad de la información" en el entorno urbano, dificultando la comprensión a cualquier persona que necesite procesar tal concentración de información (Fundación ONCE, 2009). Para que el entorno urbano sea accesible cognitivamente, sus servicios deben organizarse de modo que cualquier persona pueda desenvolverse en ellos de la manera más independiente, segura y natural posible (Juncà, 2002).

Se elige específicamente el metro de Valparaíso ya que conecta múltiples localidades de la zona, registrando aproximadamente 19.468 .000 pasajeros en el año 2017. Corresponde a un servicio de transporte sistematizado y fácil de usar, ya que a diferencia del transporte local de buses y colectivos, el Metro de Valparaíso tiene estaciones y horarios precisos, que permiten a sus usuarios informarse, organizar su viaje y hacer uso de los servicios de manera oportuna.

Para optimizar el uso de los servicios, se propone descomponerlos en tareas específicas, por ejemplo, en el caso del metro algunas de ellas serían cargar la tarjeta, trasladarse de un punto a otro, entre otras. Esto entrega mayor control de las actividades que se pueden realizar en este servicio.

\section{Resultados o hallazgos}

La discapacidad intelectual es un concepto inmerso en el modelo social de la discapacidad, ya que pone acento en los componentes contextuales que actúan como barreras o facilitadores para que la persona pueda acceder a uno u otro entorno. El problema de la discapacidad intelectual ya no se sitúa "en" la 


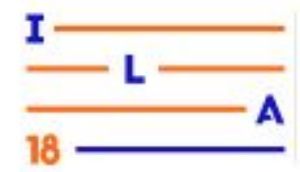

persona, sino que se desplaza hacia el entorno, entendiendo a éste como las situaciones donde las personas con discapacidad intelectual se desenvuelven (Fundación ONCE, 2009).

\section{Referencias espaciales}

Queda en evidencia mediante este estudio que es importante la precisión al momento de definir un lenguaje pictográfico, ya que éste actúa como puente entre la persona con discapacidad intelectual y el espacio, permitiéndole asociar -o no- el plano gráfico con el físico.

Cuando un pictograma tiene la función de señalar o indicar un lugar en específico, éste debe ser literal en relación a los objetos presentes en el entorno. De esta manera, se evita la dependencia de la memorización y la necesidad de usar habilidades organizativas complejas, facilitando la lectura del espacio (Fundación ONCE, 2009).

Esto se evidenció mayoritariamente en la sonda del Museo de Historia Natural, donde se generaron confusiones en las personas con discapacidad intelectual al ver pictogramas en el mapa representando imágenes que no estaban en el espacio real. Por ejemplo, el símbolo de un Moai que representaba la sala de Isla de Pascua. Al no existir ningún Moai en la sala del museo, el grupo asesor no fue capaz de distinguir que había llegado a su destino.

A partir de esto, se comprende la importancia de relevar los hitos o landmarks del entorno a las ilustraciones pictográficas para mejorar la comunicación, como un elemento y recurso clave para la navegación espacial de la persona con discapacidad intelectual.

\section{Secuencias}

Las capacidades cognitivas de las personas con discapacidad intelectual afectan en el diseño del sistema de ilustraciones pictográficas. Éstas hacen referencia a cómo ellos procesan la información, cómo perciben el espacio y sus elementos, su capacidad de memorizar trayectos o tareas específicas, la comprensión de lo que están realizando en relación al espacio, el establecimiento de analogías, entre otras (Fundación ONCE, 2009).

Para esto, la entrega de la información en menor cantidad y manera secuencial toma un rol indispensable. Al descomponer una tarea en pasos simples, se acompaña a la persona en el proceso, actuando como un apoyo visual y entregando seguridad de que lo que está haciendo es lo correcto.

Este apoyo debe agotar en lo posible, todas las opciones para hacer de la información algo accesible. Entonces, tendrá que considerar abarcar al menos tres canales de comunicación: audio, texto y pictogramas (Fundación ONCE, 2009).

A partir de esto se plantea que la muestra de la información de cada paso de las secuencias se mostrará en estos tres formatos, teniendo jerarquías definidas por los niveles de comunicación de cada uno.

El uso de pictogramas facilita el acceso de la información, haciendo visibles los recursos y servicios de los que puede beneficiarse (Rodrigo \& Anaut, 2016), ya que debido a su brevedad visual comunican un mensaje claro y transversal (Larraz, 2015).

Es por esto que se define que la ilustración pictográfica adquiere el rol de ser la mayor fuente de comunicación dentro del apoyo, acompañado de un ícono ubicado sobre la instrucción en texto, estos deben complementar la información entregada.

\section{Composición del apoyo}

El apoyo debe agotar todas las opciones para comunicar de manera accesible la información que se quiere entregar. Para lograr esto tiene que abarcar al menos tres canales de comunicación: audio, texto y pictogramas (Fundación ONCE, 2009).

Basado en esto se decide ocupar tres elementos para la composición del apoyo: la ilustración, que entrega al usuario una vista general de lo que está 


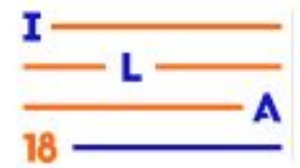

sucediendo; el ícono que acentúa y hace evidente la acción del protagonista y la instrucción, que debe estar escrita en lectura fácil, esto quiere decir que debe ser una frase breve, legible y concreta para que ésta sea accesible para personas con discapacidad intelectual (Fig. 1).

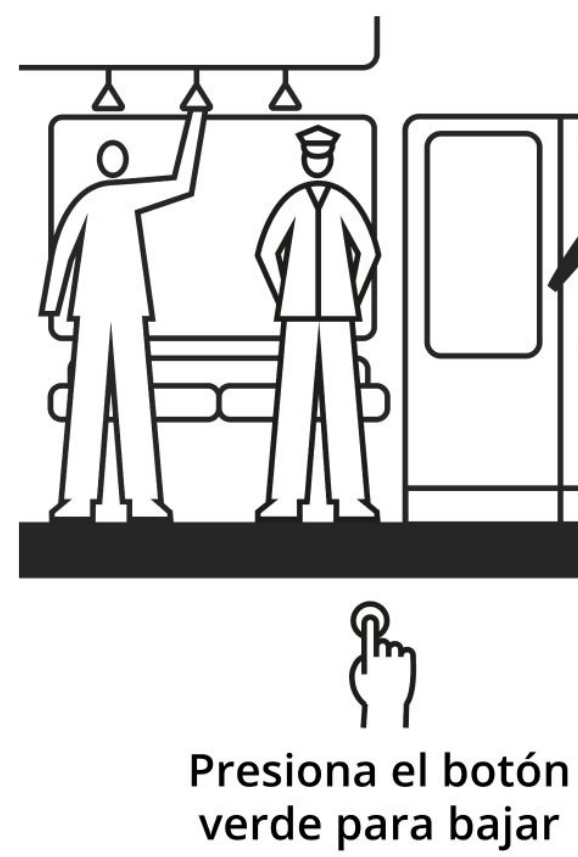

Fig 1. Composición del apoyo para el Metro de Valparaíso.

Tarea: Viajar.

Ícono: Presionar.

Instrucción (paso 5): Presiona el botón verde para bajar.

\section{Profundidad por capas}

Cada ilustración pictográfica tiene una densidad comprendida en tres capas. Esta construcción entrega mayor precisión en la comunicación, al abarcar (1) contexto, (2) hitos y (3) acción.

Lynch (1960) define los hitos en el wayfinding como objetos singulares, únicos o memorables en un contexto determinado. En este caso, los hitos corresponden a objetos reales presentes en el paso representado por la ilustración pictográfica y que puede ser reconocido por el usuario del servicio al realizar la acción.

La construcción de las ilustraciones pictográficas en capas simplifica la determinación de los elementos que componen cada una de ellas. De esta manera, se crea una estructura sistematizable para la construcción de nuevas ilustraciones, permitiendo la expansión de la fuente de elementos pictográficos de las ilustraciones y la posibilidad de ser replicada en otros servicios.

Se determinó un total de cinco tareas propias del Metro de Valparaíso para construir en secuencias de ilustraciones pictográficas: Viajar, sacar la tarjeta, sacar la tarjeta de beneficio tarifario, cargar la tarjeta y reciclar (el Metro de Valparaíso ofrece la posibilidad de cargar saldo mediante el reciclaje de botellas en máquinas establecidas). A continuación se presenta una tabla en donde se muestra la construcción de la tarea "viajar".

\begin{tabular}{|c|c|c|c|}
\hline Paso & $\begin{array}{l}\text { Capa de } \\
\text { Contexto }\end{array}$ & $\begin{array}{l}\text { Capa del } \\
\text { Hito }\end{array}$ & $\begin{array}{l}\text { Capa de la } \\
\text { Acción }\end{array}$ \\
\hline $\begin{array}{l}\text { Pasa tu tarjeta } \\
\text { por el sensor } \\
\text { torniquete }\end{array}$ & $\begin{array}{l}\text {-Suelo } \\
\text {-Cartel } \\
\text {-Valla } \\
\text { divisoria }\end{array}$ & $\begin{array}{l}\text {-Torniquete } \\
\text {-Guardia }\end{array}$ & $\begin{array}{l}\text {-Protagonista } \\
\text { manipulando } \\
\text { tarjeta }\end{array}$ \\
\hline $\begin{array}{l}\text { Dirígete al } \\
\text { andén } \\
\text { correspondiente }\end{array}$ & $\begin{array}{l}\text {-Suelo } \\
\text {-Cartel } \\
\text {-Asiento }\end{array}$ & $\begin{array}{l}\text {-Escalera } \\
\text {-Extra en } \\
\text { posición de } \\
\text { espera }\end{array}$ & $\begin{array}{l}\text {-Protagonista } \\
\text { bajando la } \\
\text { escalera }\end{array}$ \\
\hline $\begin{array}{l}\text { Espera el metro } \\
\text { detrás de la } \\
\text { línea }\end{array}$ & $\begin{array}{l}\text {-Andén } \\
\text {-Cartel }\end{array}$ & $\begin{array}{l}\text {-Metro de } \\
\text { frente }\end{array}$ & $\begin{array}{l}\text {-Protagonista } \\
\text { esperando }\end{array}$ \\
\hline $\begin{array}{l}\text { Sube al metro } \\
\text { después que la } \\
\text { gente baje }\end{array}$ & -Suelo & $\begin{array}{l}\text {-Metro de } \\
\text { perfil con la } \\
\text { puerta } \\
\text { abierta } \\
\text {-Extra } \\
\text { dentro del } \\
\text { metro }\end{array}$ & $\begin{array}{l}\text {-Protagonista } \\
\text { esperando }\end{array}$ \\
\hline $\begin{array}{l}\text { Presiona el } \\
\text { botón verde } \\
\text { para bajar }\end{array}$ & $\begin{array}{l}\text {-Suelo } \\
\text {-Ventana } \\
\text {-Asiento } \\
\text {-Barra } \\
\text { superior }\end{array}$ & $\begin{array}{l}\text {-Puerta del } \\
\text { interior del } \\
\text { metro } \\
\text {-Guardia } \\
\text {-Extra } \\
\text { afirmándose } \\
\text { de la barra } \\
\text { superior }\end{array}$ & $\begin{array}{l}\text {-Protagonista } \\
\text { presionando } \\
\text { botón }\end{array}$ \\
\hline $\begin{array}{l}\text { Sube a la } \\
\text { boletería por la } \\
\text { escalera }\end{array}$ & $\begin{array}{l}\text {-Suelo } \\
\text {-Cartel } \\
\text {-Asiento }\end{array}$ & $\begin{array}{l}\text {-Escalera } \\
\text {-Extra en } \\
\text { posición de } \\
\text { espera }\end{array}$ & $\begin{array}{l}\text {-Protagonista } \\
\text { subiendo la } \\
\text { escalera }\end{array}$ \\
\hline $\begin{array}{l}\text { Pasa tu tarjeta } \\
\text { por el sensor } \\
\text { torniquete }\end{array}$ & $\begin{array}{l}\text {-Suelo } \\
\text {-Cartel }\end{array}$ & $\begin{array}{l}\text {-Torniquete } \\
\text {-Guardia }\end{array}$ & $\begin{array}{l}\text {-Protagonista } \\
\text { manipulando } \\
\text { tarjeta }\end{array}$ \\
\hline
\end{tabular}




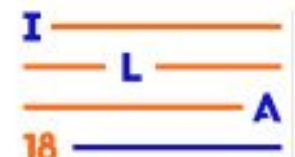

\begin{tabular}{|l|l|l|l|}
\hline & $\begin{array}{l}\text {-Valla } \\
\text { divisoria }\end{array}$ & & \\
\hline $\begin{array}{l}\text { Busca la salida } \\
\text { de la estación }\end{array}$ & $\begin{array}{l}\text {-Suelo } \\
\text {-Cartel }\end{array}$ & $\begin{array}{l}\text {-Salida } \\
\text {-Extra } \\
\text { caminando }\end{array}$ & $\begin{array}{l}\text {-Protagonista } \\
\text { caminando } \\
\text { hacia la } \\
\text { salida }\end{array}$ \\
\hline
\end{tabular}

Tabla 3. Detalle de la construcción de la tarea "viajar".

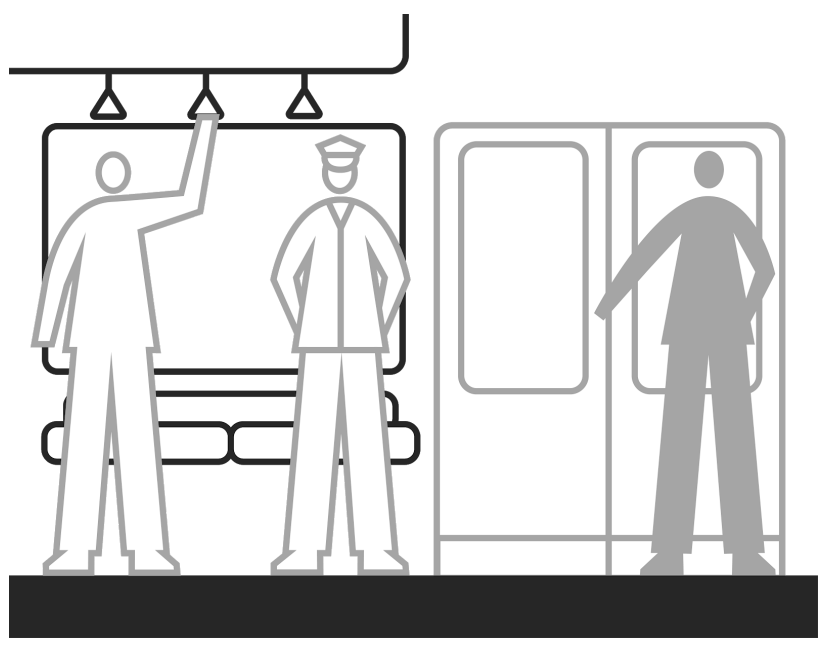

Fig 2. Desglose capa 1 de contexto: Espacio y referentes.

En esta "meta-capa" se ubican las referencias espaciales cuyo objetivo es contextualizar el plano físico. Es una capa que no tiene incidencia directa en la transacción de la ilustración individual, pero le brinda contexto a la secuencia total, ya que muestra "lo que hay" en el espacio. Es la encargada de generar continuidad y coherencia visual.

Esta capa puede contener dos tipos de elementos.

- Tipo 1: Objetos físicos contextuales.

- Tipo 2: Señalética propia del espacio.

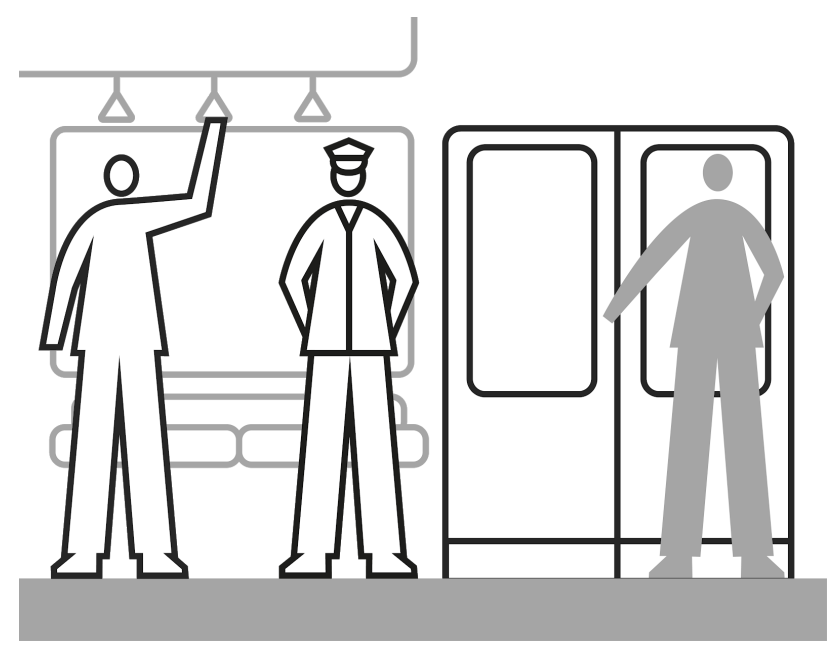

Fig 3. Desglose capa 2 de hito. Artefactos y personas del servicio

En esta capa se ubican las referencias espaciales y humanas que participarán de la acción en cada paso, es decir, el hito o landmark. El hito es primordial para llevar cada paso de la secuencia al plano físico, ya que es el elemento que hace representativo su contenido. Es la capa encargada de garantizar que la acción del protagonista se entienda.

Esta capa puede contener tres tipos de elementos.

- Tipo 1: Objeto físico propio que participa activamente en la transacción.

- $\quad$ Tipo 2: Personajes (blancos) involucrados en la acción que son parte del servicio y participan activamente en la transacción.

- Tipo 3: Extras (blancos) que anticipan al usuario al momento de enfrentarse a una de las tareas, presentando la escena lo más cercana a la realidad posible. 
Interaction Latin America

Rio de Janeiro, Brasil - 2018

http://ila.ixda.org/2018

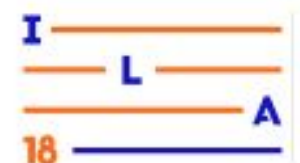

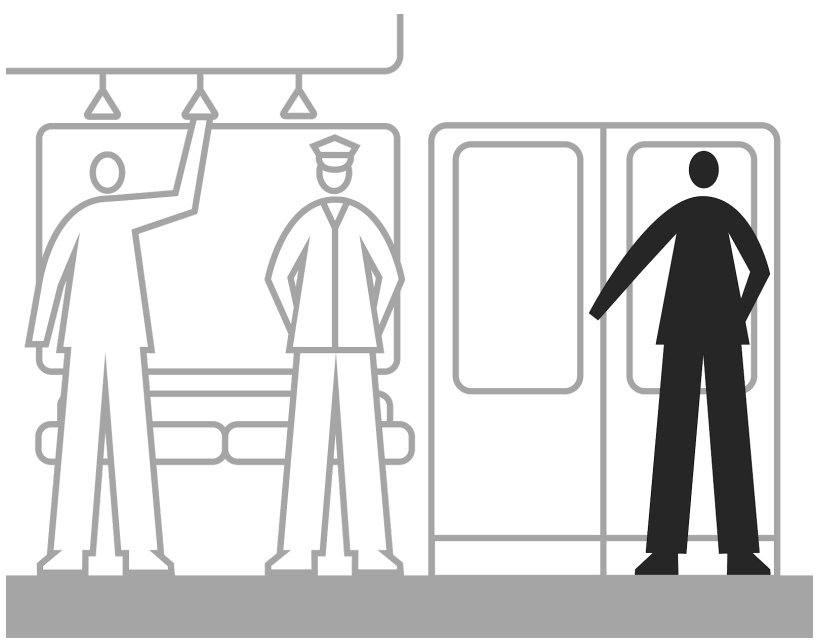

Fig 4. Desglose capa 3 de acción. Acciones del protagonista.

En esta capa se ubica el núcleo que articula la transacción que se lleva a cabo en cada paso. La gestualidad del protagonista deberá ser clara, para que al verla en relación a la capa de artefactos y personajes, se entienda la acción a realizar en su contexto. El elemento humano deberá estar presente en todo momento, puesto que sin él, no habrá acción.

Esta capa puede contener dos tipos de elementos.

- Tipo 1: Persona protagonista (cuerpo negro entero o partes de él).

- Tipo 2: Elementos gráficos que no forman parte del espacio físico, pero que cumplen la función de acentuar la acción del protagonista, tales como tarjetas, dinero, documentos, tickets de atención, entre otros.

\section{Proyecciones}

Actualmente se ha desarrollado la totalidad de los pasos de las tareas: ir de un punto a otro, sacar la tarjeta, sacar la tarjeta de beneficio tarifario, cargar la tarjeta, conectarse a wifi y reciclar; las tareas más demandadas por los usuarios del Metro de Valparaíso, según las preguntas frecuentes que se encuentran en su sitio web. Se espera finalizar el diseño de todas las ilustraciones pictográficas para la totalidad de las tareas relativas a este servicio, para luego desarrollar las plataformas en donde éstas serán utilizadas.
Posteriormente, se pretende seguir con la investigación, corroborando mediante tests de usabilidad y la validación constante del grupo asesor, cómo es que estas ilustraciones pictográficas inciden en la autodeterminación de las personas con discapacidad intelectual.

Este sistema de ilustraciones pictográficas se pensó para ser visualizado en tres formatos, dos análogos y uno digital. El primer formato análogo consistirá en un afiche, cuyo su objetivo será ser visualizado por el mayor número de personas de manera simultánea, para generar un mejor alcance de la información. Permanecerá en el lugar físico más visible y dispondrá de todas las tareas y transacciones que se puedan realizar en éste. El segundo formato análogo consistirá en una impresión de todas las tareas a realizar en el servicio, en formato transportable. De esta manera, la persona podrá llevar consigo la información.

El formato digital también tiene como propósito permitir que la persona pueda llevar consigo la información. Esto se llevará a cabo a través del celular, escaneando un código QR, el cual abrirá el sitio del servicio, mostrando el total de las tareas, con la posibilidad de elegir la que se quiere realizar, $\mathrm{y}$ ver su paso a paso.

La idea es que este sistema pueda ser replicable y expandible no solo en el servicio del metro, si no que en todos los servicios públicos y privados posibles, para aportar en la construcción de un país más inclusivo y consciente.

\section{Conclusiones}

La investigación y diseño de herramientas que aumenten la autodeterminación, es especialmente relevante considerando el porcentaje de población que presenta algún nivel de discapacidad intelectual en Chile. Cabe considerar además que estas cifras aumentan con el envejecimiento de la población.

Para diseñar ilustraciones pictográficas que incidan positivamente en la autodeterminación de los adultos con discapacidad intelectual en Valparaíso, se trabajó constantemente bajo una metodología interdisciplinaria y colaborativa con el grupo asesor. 


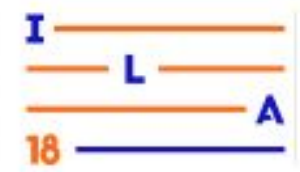

El trabajo interdisciplinario permitió integrar las perspectivas de las distintas disciplinas académicas que se vieron involucradas, donde cada miembro cumplía un rol específico.

Por otro lado, la participación del grupo asesor en los talleres se considera un factor diferenciador en esta investigación, por la calidad de validador y evaluador que tiene cada miembro, entregando resultados cualitativos empíricos.

Cada taller permitió desarrollar un espacio de trabajo simétrico, donde tanto el equipo interdisciplinario como el grupo asesor tuvieron la posibilidad de generar intercambio de ideas, las cuales luego serían analizadas y trabajadas por el equipo para aportar a la investigación.

Como principales conclusiones de la investigación, se destaca que el uso de pictogramas debe ser siempre literal en relación a los objetos presentes en el entorno para mejorar la comunicación entre la persona y el espacio. Si esto se cumple, se evita la dependencia de la memorización y la necesidad de usar habilidades organizativas complejas, facilitando la lectura del espacio.

Adicionalmente, la entrega de la información de manera secuencial toma un rol indispensable para las transacciones de los servicios. Cada secuencia debe ser mostrada con un orden claro ya que al acompañar a la persona en el proceso, actúa como un apoyo visual, entregando la seguridad de que lo que está haciendo es lo correcto.

Por esto, se propone que la muestra de la información de los pasos de cada pictograma de una secuencia debe considerar tres formatos: pictograma, texto y audio, teniendo jerarquías previamente definidas por los niveles de comunicación de cada uno, donde la ilustración pictográfica adquiere el rol de ser la mayor fuente de comunicación, complementada por el ícono, que acentúa la acción del protagonista y la instrucción en texto que debe estar escrita en lectura fácil.

Cada instrucción debe considerar la existencia de la acción y la presencia de un hito, que ayude a situar en el espacio a la persona.
En relación a las conclusiones de la propuesta de ilustraciones pictográficas, es importante que ésta sea sistematizada, esto permite la expansión de la fuente de elementos pictográficos, además de entregar la posibilidad de ser replicada en otros servicios.

Cada ilustración debe estar comprendida en capas. Esto entrega mayor precisión en la comunicación, ya que se abarca un elemento del espacio (capa de contexto), otro elemento relacionado con la acción (capa de la acción) y un tercero relacionado con los elementos que participan en ella (capa del hito).

Actualmente se han diseñado la totalidad de las tareas que son más demandadas por los usuarios en el Metro de Valparaíso, de acuerdo a las preguntas frecuentes en el sitio web del servicio. Se pretende a futuro diseñar el resto de tareas que se pueden realizar en este lugar, además de desarrollar sus plataformas de visualización.

Futuras investigaciones podrán realizarse para observar cómo es que la propuesta de ilustraciones pictográficas incide en la autodeterminación de las personas con discapacidad intelectual. El objetivo último, es que este sistema logre replicarse y expandirse a otros servicios públicos y privados.

De esta manera, se pretende aportar a la construcción de una sociedad en donde cada persona pueda vivir libremente y sin impedimentos, teniendo la posibilidad de navegar y entender el entorno urbano sin ningún tipo de discriminación debido a sus capacidades cognitivas.

\section{Agradecimientos}

Este trabajo es parte del proyecto de investigación asociativa "I2 - Investigación Inclusiva: Oportunidades para fortalecer la autodeterminación en la era digital" Código 039.464/2017 financiado por la Pontificia Universidad Católica de Valparaíso, Chile. También forma parte del proyecto "Red Científica Interdisciplinaria de investigación e innovación en Discapacidad Intelectual y/o del Desarrollo (REIDI)" financiado por CONICyT, Chile. 


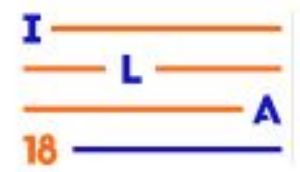

Agradecemos a cada miembro del equipo interdisciplinario. A Miguel Osorio (Profesor), Nicolás Fuenzalida (Sociólogo), Paulina Carrasco (Estudiante de Educación Diferencial), Rodolfo Villarroel (Ingeniero informático), Oscar Arancibia (Estudiante de Ingeniería Informática) y Mauricio Díaz (Psicólogo), por su trabajo y aportes desde sus áreas.

A la Pontificia Universidad Católica de Valparaíso, específicamente a la Escuela de Arquitectura y Diseño, a la Escuela de Pedagogía y al Instituto de Historia, por darnos la posibilidad de hacer uso de sus espacios y prestaciones para los talleres colaborativos, las reuniones interdisciplinarias y las jornadas de trabajo.

Al Museo de Historia Natural de Valparaíso, por haber facilitado sus dependencias para llevar a cabo la aplicación de la sonda.

A todos los miembros del grupo asesor, por su buena disposición en todo el proceso de investigación.

Al Metro de Valparaíso, por haber facilitado sus dependencias para el proceso de investigación.

\section{Referencias bibliográficas}

American Association on Intellectual and Developmental Disabilities. The AAIDD Definition of Intellectual Disability is Cited in SSA's Proposed Revision of Medical Criteria for Evaluating Mental Disorders. Disponível em:

$<$ https://aaidd.org/news-policy/news/releases/2010/0 9/01/the-aaidd-definition-of-intellectual-disability-is -cited-in-ssa-s-proposed-revision-of-medical-criteria -for-evaluating-mental-disorders\#.W1H8eNhKiRs> Acesso em: 20 de julho de 2018.

Aguas, S. ¿Qué es el co-design? Algunas ideas sobre esta beneficiosa práctica. Disponível em: $<$ https://www.unibarcelona.com/int/actualidad/artesgraficas/co-design $>$. Acesso em: 30 de junho de 2018.

Asociación ASPADEX. Accesibilidad cognitiva y discapacidad intelectual. Disponível em:

$<$ https://aspadex.org/accesibilidad-cognitiva-y-disca pacidad-intelectual/>. Acesso em: 30 de junho de 2018.

Bosch, S. J.; Gharaveis, A. Flying solo: A review of the literature on wayfinding for older adults experiencing visual or cognitive decline. Applied Ergonomics. Volume 58, 2017. p 327-333

Costa, J. Señalética (de la señalización al diseño de programas). Barcelona: Enciclopedia del Diseño, 1987.

Fundación ONCE. Accesibilidad y capacidades cognitivas. Movilidad en el entorno urbano. Vialidad, transporte y edificios públicos, 2009.

García, D. Diseño de sistemas de orientación espacial. Wayfinding. Madrid: Accesibilidad Universal y Diseño para Todos. Arquitectura y Urbanismo, 2012.

Juncà, A. Accesibilidad Universal. Diseño sin discriminación. Madrid: IMSERSO y Obra Social, 2002.

Kapstein, P. Análisis de asentamientos precarios en Valparaíso y su incidencia en el crecimiento urbano. Santiago de Chile: Revista INVI. Volumen 19, 2009.

Kitchin, R.M. Cognitive maps: what are they and why study them? Journal of Environmental Psychology. Volume 14, 1994.

Larraz, C. Accesibilidad cognitiva Colección: 12retos, 12 meses Número: 10. Madrid: CEAPAT, 2015.

Lynch, K. The Image of the City. Cambridge, Massachusetts: The Technology Press and the Harvard University Press, 1960

Márquez, D.X.; Hunter, R.H.; Griffith, M.H.; Bryant, L.L.; Janicek, S.J.; Atherly, A.J. Older adult strategies for community wayfinding. Journal of Applied Gerontology, 2015.

Passini, R. Spatial representations, a wayfinding perspective. Journal of Environmental Psychology. Volume 4, 1984. 
Puyalto, C. La vida independiente de las personas con discapacidad intelectual. Análisis de los apoyos y las barreras que inciden en la consecución de sus proyectos de vida. Granada: Universitat de Girona, 2016.

Rodrigo, A.; Anaut, S. Accesibilidad cognitiva, un derecho invisible: Guía adaptada de recursos para la inclusión de las personas con discapacidad intelectual. Navarra: Universidad Pública de Navarra, 2016.

Rodríguez-Sánchez, E.; Mora-Simón, S.; Patino-Alonso, M. et al. Prevalence of cognitive impairment in individuals aged over 65 in urban area: DERIVA study. BMC Neurology, 2011.

Rojas, S. Autodeterminación y calidad de vida en personas discapacitadas. Experiencia desde un hogar de grupo. Barcelona: Universitat Autònoma de Barcelona, 2004.

Sanders, E. Co-creation and the new landscapes of design. Taylor \& Francis. Volume 4, 2008.

SENADIS. II Estudio Nacional de la Discapacidad en Chile. Santiago: Servicio Nacional de la Discapacidad, 2016.

Vega, V.; Álvarez, I.; Jenaro, C. Autodeterminación: Explorando las autopercepciones de adultos con Síndrome de Down chilenos. Salamanca: Siglo Cero. Volumen 49, 2016.

Williams, R. Creating a new world of opportunity: Expanding choice and self-determination in lives of Americans with severe disability by 1992 and beyond. Minneapolis: Institute on Community Integration, 1989. 